$$
N 63-13767
$$

Technical Report No. 32-368

\title{
Thermal Properties of a Simulated Lunar Material in Air and in Vacuum
}

E. C. Bernett

H. L. Wood

L. D. Jaffe

H. E. Martens

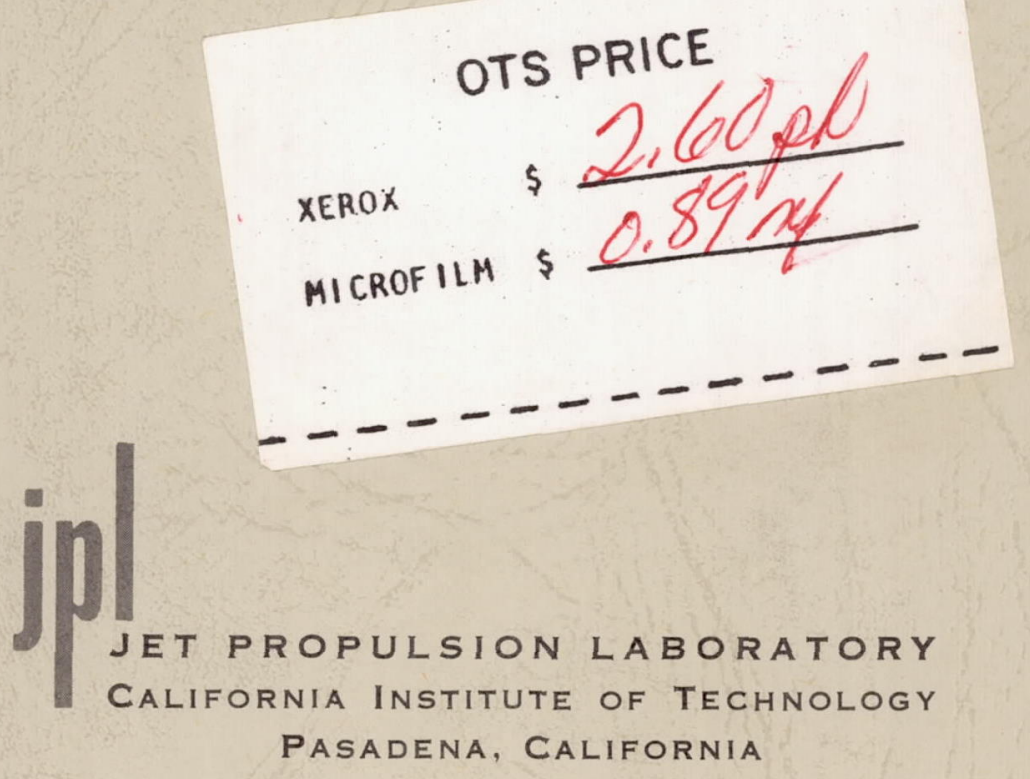

November 25, 1962 
National Aeronautics and Space Administration CONTRACT No. NAS 7-100

Technical Report 32-368

\title{
Thermal Properties of a Simulated Lunar Material in Air and in Vacuum
}

\author{
E. C. Bernett \\ H. L. Wood \\ L. D. Jaffe \\ H. E. Martens
}

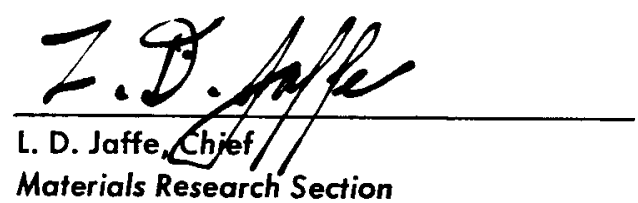

Materials Research Section

\author{
JET PROPULSION LABORATORY \\ CALIFORNIA INSTITUTE OF TECHNOLOGY \\ PASADENA, CALIFORNIA
}

November 25, 1962 


\section{Copyright (C) 1963}

Jet Propulsion Laboratory California Institute of Technology 


\section{CONTENTS}

I. Introduction . . . . . . . . . . . . . . . . . . . 1

II. Materials Tested . . . . . . . . . . . . . . . . . . . 2

III. Test Apparatus and Experimental Procedure . . . . . . . . 3

IV. Evaluation of Measurements . . . . . . . . . . . . . . 7

V. Discussion of Results . . . . . . . . . . . . . . . . . . 13

VI. Conclusions . . . . . . . . . . . . . . . . . . . . . 14

Appendix . . . . . . . . . . . . . 15

References . . . . . . . . . . . . . . . . . . . . 19

\section{TABLES}

1. Particle size distribution of materials tested . . . . . . . . . . . 2

2. Thermal diffusivity and conductivity of $70-$ mesh $99 \%$ silica sand . . . . . 6

3. Thermal diffusivity and conductivity of $-35+48$ mesh olivine basalt . 7

4. Thermal diffusivity and conductivity of $\mathbf{- 3 5}$ mesh olivine basalf . . 8

5. Thermal diffusivity and conductivity of -150 mesh olivine basalt . . . 12

A1. Error summary . . . . . . . . . . . . . . . . . . . . . 16

\section{FIGURES}

1. Thermal diffusivity test equipment . . . . . . . . . . . . . . 3

2. Details of specimen holder . . . . . . . . . . . . . . . . 4

3. Temperature vs time for vacuum test 9-11 lolivine basalt $-35+48$ mesh af a density of $97\left(\mathrm{~b} / \mathrm{ft}^{3} \mathrm{l}\right.$. . . . . . . . . . . . . . . 5

4. Change in temperature of infinite cylinder caused by sudden change of surface temperature from Ref. 5 and 6 . . . . . . . . 5

5. Specific heat vs temperature (silica sand data from Ref. 7 and 8) . . 7

6. Thermal diffusivity and conductivity vs temperature of $99 \%$ silica sand . . . . . . . . . . . . . . . . . . . . . . 9

7. Thermal diffusivity and conductivity vs temperature of $-35+48$ mesh olivine basalt . . . . . . . . . . . . . . . . . . . 9

8. Thermal diffusivity and conductivity vs temperature of -35 mesh olivine basalt . . . . . . . . . . . . . . . . . . . 10

9. Thermal diffusivity and conductivity vs temperature of -150 mesh olivine basalt . . . . . . . . . . . . . . . . . . . 10

10. Thermal diffusivity and conductivity vs temperature of olivine basalt . . 11 


\begin{abstract}
The thermal diffusivity and thermal conductivity for a crushed olivine basalt were determined from transient state data. Values were obtained over a temperature range of -100 to $200^{\circ} \mathrm{C}$ in vacuums of $5 \times 10^{-3}$ and $5 \times 10^{-6} \mathrm{~mm} \mathrm{Hg}$ as well as at atmospheric pressure. A - 150 mesh material at a density of $1.14 \mathrm{~g} / \mathrm{cm}^{3}$ had a thermal conductivity of $3.9 \times 10^{-6} \mathrm{cal} / \mathrm{cm} \mathrm{sec}{ }^{\circ} \mathrm{C}$ at $100^{\circ} \mathrm{C}$ when measured in a vacuum of $5 \times 10^{-16} \mathrm{~mm} \mathrm{Hg}$. This was approximately one hundred times lower than the values obtained for the same material measured at atmospheric pressure. Increasing the density to $1.57 \mathrm{~g} / \mathrm{cm}^{3}$ increased the thermal conductivity by approximately $60 \%$ in both air and vacuum. Over the range studied, the test temperature had very little effect on thermal conductivity in air but showed more of an effect when the material was placed in a vacuum.
\end{abstract}

\title{
I. INTRODUCTION
}

In preparation for manned landings on the Moon, research aimed at determining the physical and mechanical properties of the postulated lunar surface is now in progress. There have been extensive astronomical studies of the Moon and its surface; on the basis of these, it is proposed that the Moon is composed of igneous rocks similar to certain types that are found on Earth. Some measurements (Ref. 1, 2, 3), however, indicate that the thermal conductivity of the lunar surface is extremely low-much lower than that of any known types of consolidated rock. To account for this, it is postulated that large portions of the lunar surface are covered with a highly porous material, probably powdery, perhaps lightly sintered.

The investigation described here is one part of a program designed to evaluate the properties of a powdered rock simulating the postulated lunar surface material. Its purpose was to measure the effects of vacuum on the thermal diffusivity and conductivity of rock powder. 


\section{MATERIALS TESTED}

The material used in the initial runs, which were designed to check equipment operation, was a 70-mesh commercial grade $99 \%$ silica foundry sand. The particle size distribution of this material is given in Table 1 . The moisture content was less than $0.03 \%$.

The material selected to simulate lunar material for this study was an olivine basalt collected from Pisgah Crater, San Bernardino County, California. The large volcanic bombs were crushed to about 3 -in. size using a hydraulic press. Any pieces which appeared to be contaminated or which showed signs of weathering were discarded. The remaining material was passed through a Gates jaw crusher and a stainless-steel hammer milltype pulverizer to reduce it all to -35 mesh material. A detailed mineralogical description of this material and the crushing procedure is given in Ref. 4.

Most of the -35 mesh material was screened into more closely sized fractions; nominally $-35+48,-48+65$, $-60+100,-100+150$, and -150 mesh. Actual screen analyses of the fractions used for the thermal conductivity tests are shown in Table 1 .

The "as received" density of the rock as measured by water displacement was $2.83 \mathrm{~g} / \mathrm{cm}^{3}$ at $24^{\circ} \mathrm{C}$. The density of the crushed material was $2.97 \mathrm{~g} / \mathrm{cm}^{3}$. All of the screened fractions were stored in closed containers. Measurements made during the program showed that actual moisture content varied from day to day but was always less than $0.1 \%$.

Table 1. Particle size distribution of materials tested

\begin{tabular}{|c|c|c|c|c|c|}
\hline \multirow[b]{2}{*}{$\begin{array}{c}\text { Tyler } \\
\text { mesh size }\end{array}$} & \multirow[b]{2}{*}{$\begin{array}{l}\text { Particle } \\
\text { size, } \mu\end{array}$} & \multirow[b]{2}{*}{$\begin{array}{l}99 \% \text { silica } \\
\text { sand } \\
\%\end{array}$} & \multicolumn{3}{|c|}{ Olivine basalt, \% } \\
\hline & & & $\begin{array}{c}\text { Nominal } \\
\text { mesh size } \\
-35\end{array}$ & $\begin{array}{l}\text { Nominal } \\
\text { mesh size } \\
-35+48\end{array}$ & $\begin{array}{c}\text { Nominal } \\
\text { mesh size } \\
-150\end{array}$ \\
\hline $\begin{array}{r}+28 \\
-28+35 \\
-35+48 \\
-48+65 \\
-65+100 \\
-100+150 \\
-150+200 \\
-200+270 \\
-270+325\end{array}$ & $\begin{array}{r}>590 \\
<590>420 \\
<420>297 \\
<297>210 \\
<210>149 \\
<149>105 \\
<105>74 \\
<74>53 \\
<53>44 \\
<44>35 \\
<35>25 \\
<25>12 \\
<12>7 \\
<7>3 \\
<3\end{array}$ & $\begin{array}{r}0.00 \\
0.11 \\
9.11 \\
21.12 \\
37.45 \\
25.75 \\
5.61 \\
0.37 \\
0.17\end{array}$ & $\begin{array}{r}0.05 \\
0.27 \\
8.05 \\
10.78 \\
10.26 \\
9.66 \\
9.68 \\
11.21 \\
4.94 \\
3.98 \\
9.11 \\
10.88 \\
6.31 \\
3.88 \\
0.61\end{array}$ & $\begin{array}{r}0.02 \\
0.59 \\
67.65 \\
28.80 \\
1.01 \\
0.21 \\
0.10 \\
0.09 \\
0.04 \\
0.05 \\
0.04 \\
0.26 \\
0.29 \\
0.20 \\
0.03\end{array}$ & $\begin{array}{r}0.00 \\
0.02 \\
0.03 \\
0.03 \\
2.15 \\
2.85 \\
7.98 \\
19.47 \\
14.03 \\
4.13 \\
10.70 \\
17.25 \\
9.95 \\
8.82 \\
2.08 \\
\end{array}$ \\
\hline $\begin{array}{l}\text { Total } \\
\text { Loss in screening }\end{array}$ & & $\begin{array}{r}99.69 \\
0.31 \\
100.00\end{array}$ & $\begin{array}{r}99.87 \\
0.13 \\
100.00\end{array}$ & $\begin{array}{r}99.28 \\
0.72 \\
100.00\end{array}$ & $\begin{array}{r}99.49 \\
0.51 \\
100.00\end{array}$ \\
\hline
\end{tabular}




\section{TEST APPARATUS AND EXPERIMENTAL PROCEDURE}

It was expected that very low thermal conductivity values would be obtained for the loosely packed materials in vacuum; thus, conventional equipment could not be used for these measurements, and a special apparatus was designed and built.

A general view of the equipment used is presented in Fig. 1; details of the specimen holder configuration are shown in Fig. 2. This apparatus was designed to measure the rate of change of the temperature at points along a diameter of a cylindrical specimen caused by a sudden stepped change in the outer surface temperature. To minimize errors due to heat conduction along the temperature sensors, very thin (0.003-in. D) unshielded chromel-alumel thermocouples were strung lengthwise through the specimen holder (Fig. 2). One couple was located on the centerline, two at midradius, and two at

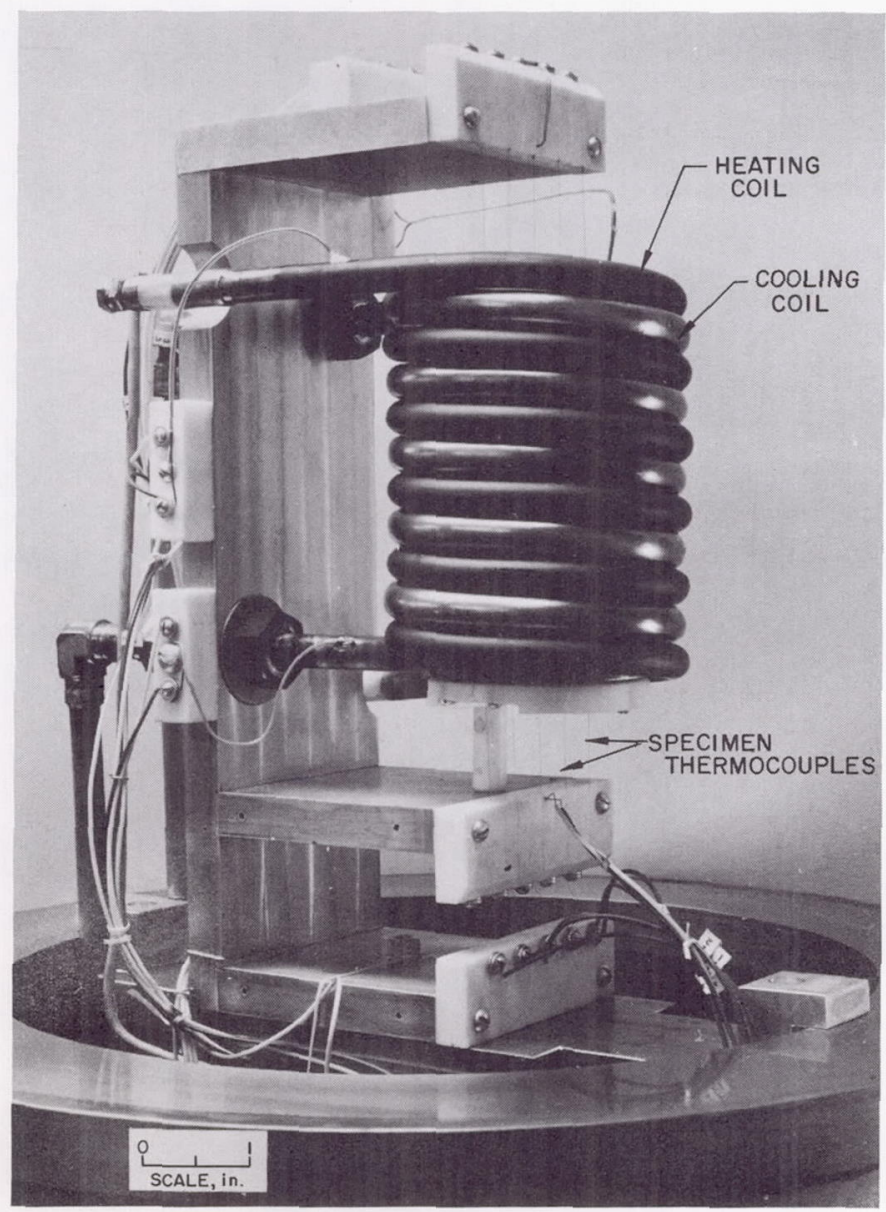

Fig. 1. Thermal diffusivity test equipment the outer surface of the specimen, which was also the inner wall of the cylindrical specimen holder. A $1500-\mathrm{w}$ hermetically sealed heating coil and a copper cooling coil were interwound on the outside of the specimen holder. A two-piece polytetrafluoroethylene closure was provided for the bottom of the holder. To increase thermal resistance between the thermocouples and the copper specimen holder, the bottom closure was so designed that it made only a line contact with the copper holder and also with the thermocouples.

A similar closure was used as a top cover during some of the preliminary runs with the thought that it would reduce radiation losses from the upper surface of the test specimen. However, it was determined that the measured diffusivities were not affected by the presence of such a cover; so, during all subsequent runs, the cover was not used, thus allowing visual observation of the surface of the specimen during the entire test.

The holder assembly and the supporting structure were attached to a double-flanged spacer which contained the vacuum leadthroughs for the thermocouples, heater cables and liquid-nitrogen supply lines. The vacuum system consisted of a 12-in. glass jar, a liquid-nitrogentrapped $4 \mathrm{in}$. oil diffusion pump ( $210 \mathrm{l} / \mathrm{sec}$ pumping speed at $8 \times 10^{-4} \mathrm{~mm} \mathrm{Hg}$ ), and a 13.3-cfm mechanical pump. Pressures on the order of $5 \times 10^{-6} \mathrm{~mm} \mathrm{Hg}$ could be reached in about $2 \mathrm{hr}$ and maintained for the duration of the test run.

Earlier studies of a similar material had indicated that the packing density had a very significant effect upon the properties (Ref. 4). Thus, it was necessary to use extreme care in loading test material into the specimen holder so that packing density could be known and controlled. To accomplish this, a known weight of the test material was loaded into the specimen holder for each run. When it was desired to conduct the experiment with a low packing density, the material was carefully spooned into the holder and every precaution taken to prevent the holder from being bumped or vibrated. The height of the material in the holder was recorded and observed during the entire test to assure that vacuum-pump vibration or other external causes did not produce a significant change in the packing density. When it was desired to conduct the experiment with a high packing density, the material was loaded in the holder, which was then tapped with a soft 

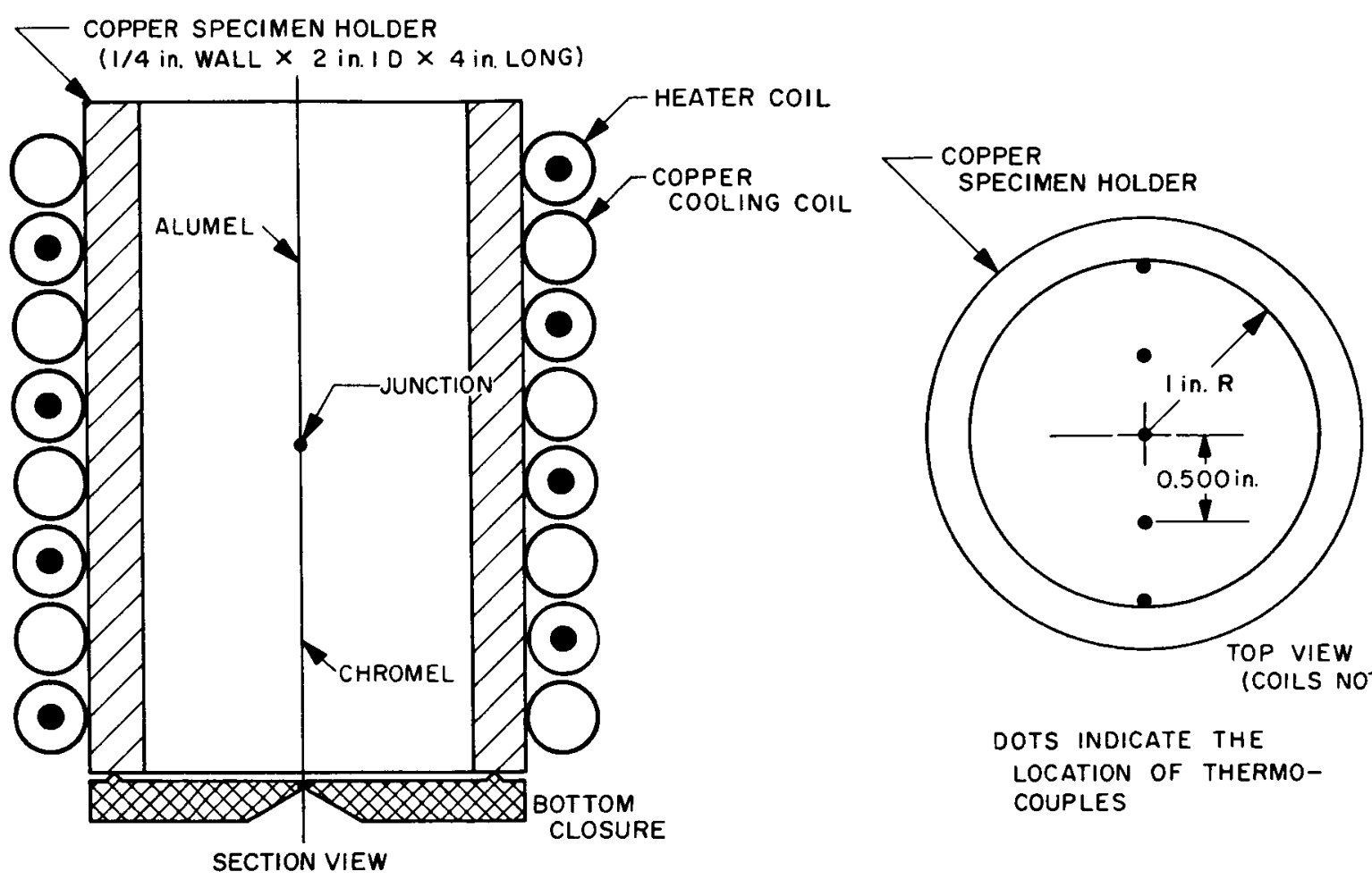

(COILS NOT SHOWN)

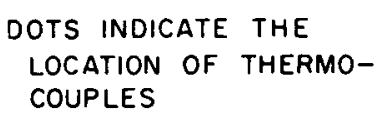

Fig. 2. Details of specimen holder

hammer until no further decrease in height of the material in the holder could be noted. Again this height was recorded and observed during the entire test to assure that degassing during evacuation did not significantly change the surface level of the test material.

After loading, the temperature of each thermocouple was read to ensure that the entire unit was thermally stabilized. When the test was to be run in vacuum, the assembly was first evacuated to the desired pressure range. The temperature of the specimen holder was then changed suddenly by energizing the heater or flowing liquid nitrogen through the cooling coil as required for a change of approximately $75^{\circ} \mathrm{F}$. This sudden temperature change was performed manually to assure maximum rate of change. An automatic controller was then used to maintain the outside wall of the specimen at the new temperature level. The outputs of the thermocouples in the test specimen (Fig. 2) were recorded on a multipoint recorder.

Each test was continued until the temperature at the center of the specimen was within about $10^{\circ} \mathrm{F}$ of the wall temperature, at which time the temperature of the holder could again be changed suddenly to extend the run to a new temperature range. In air, less than $1 \mathrm{hr}$ was required for the center temperature to reach the desired point, whereas in vacuum the time required was on the order of $36 \mathrm{hr}$. Specimen temperature vs time plots were prepared for each test. A typical example of a plot for a test in vacuum is shown in Fig. 3. In this test the initial and final temperature excesses $\left(T_{2}-T_{1}\right.$ and $T_{2}-T$; Fig. 4 and Table 2) measured for the center thermocouple were 92 and $9^{\circ} \mathrm{F}$, respectively. For the mid-radius thermocouple, the values measured were 91 and $5^{\circ} \mathrm{F}$, respectively. 


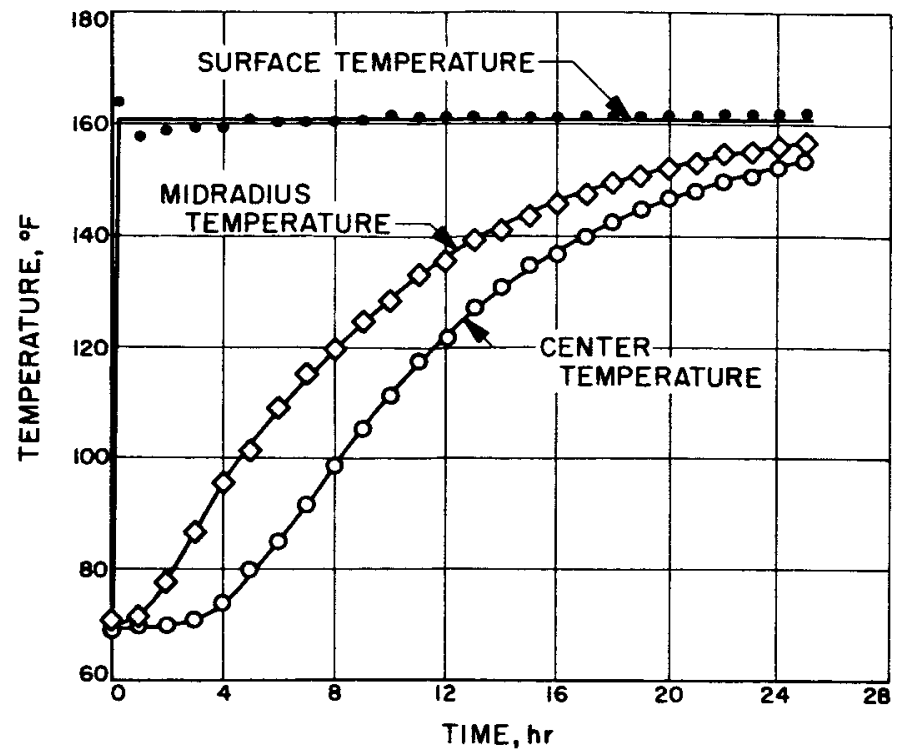

Fig. 3. Temperature vs time for vacuum test 9-11 lolivine basalt $-35+48$ mesh at a density of $\left.97 \mathrm{lb} / \mathrm{ft}^{3}\right)$

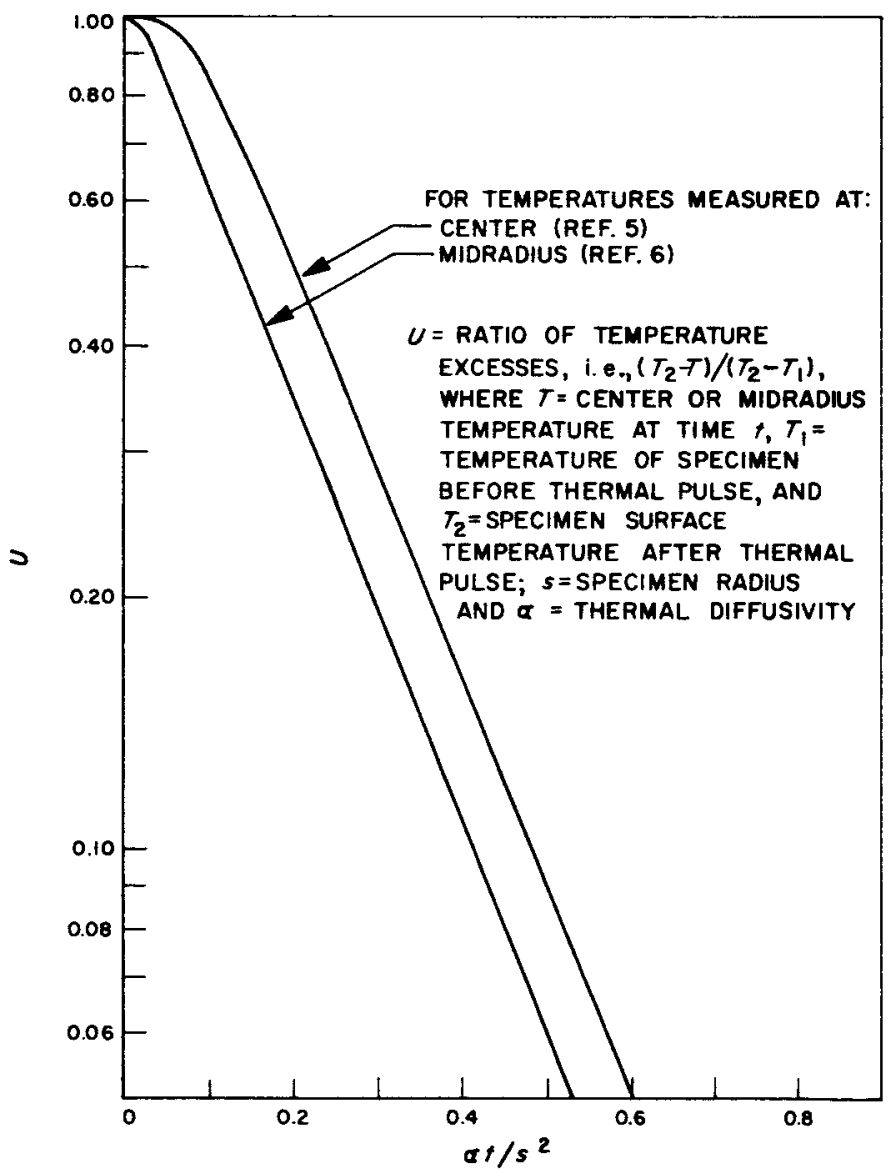

Fig. 4. Change in temperature of infinite cylinder caused by sudden change of surface temperafure 


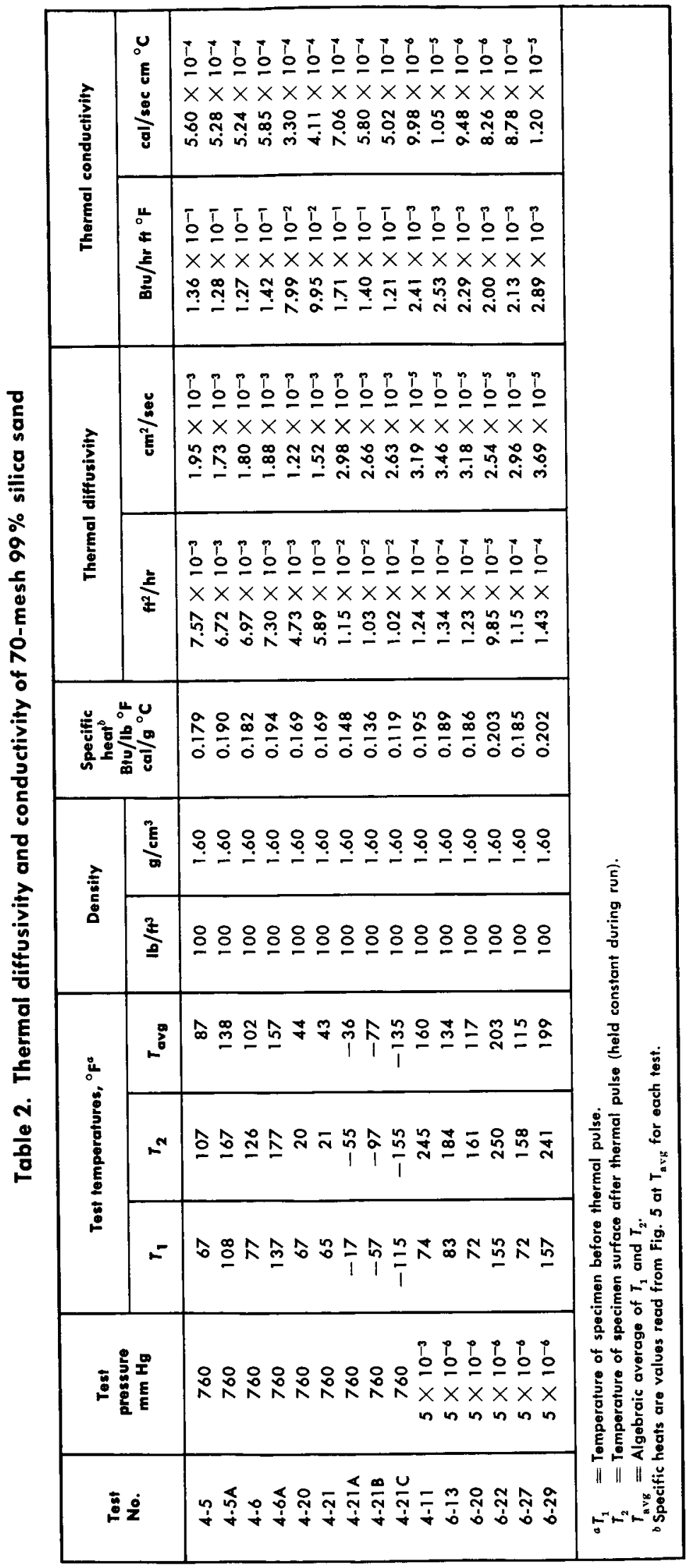




\section{EVALUATION OF MEASUREMENTS}

Methods for calculating the thermal diffusivity of a material from such transient state data are described in several texts. Jakob (Ref. 5) presents a graphical method for determining the diffusivity when the $\left(T_{2}-T\right) /\left(T_{2}-T_{1}\right)$ ratio $(U)$ of the center of a specimen of given geometry is known at any particular time. Russell (Ref. 6) describes this solution for the midradius position. These graphical methods for an infinitely long cylindrical sample are illustrated in Fig. 4. It was found from the error analysis (see Appendix) that the most accurate values of diffusivity are obtained if calculated from the segment of the time-temperature curves (Fig. 3 ) where $U$ is in the range 0.2 to 0.5 . Four diffusivity values were calculated for each test run; that is, two values from the center temperature curve at the points where $U$ was near 0.2 and 0.5 and two from the midradius temperature curve at the same $U$ values. The four diffusivities so obtained were averaged, and these average values are listed in Tables 2 through 5, inclusive.

Thermal conductivity can be calculated from diffusivity values if the density and specific heat are known. The packing density was measured for each test as indicated previously. Consistent specific-heat values for pure silica over a wide temperature range are available in the literature (Ref. 7, 8). These data are shown in Fig. 5, and were used to make the calibration calculations.

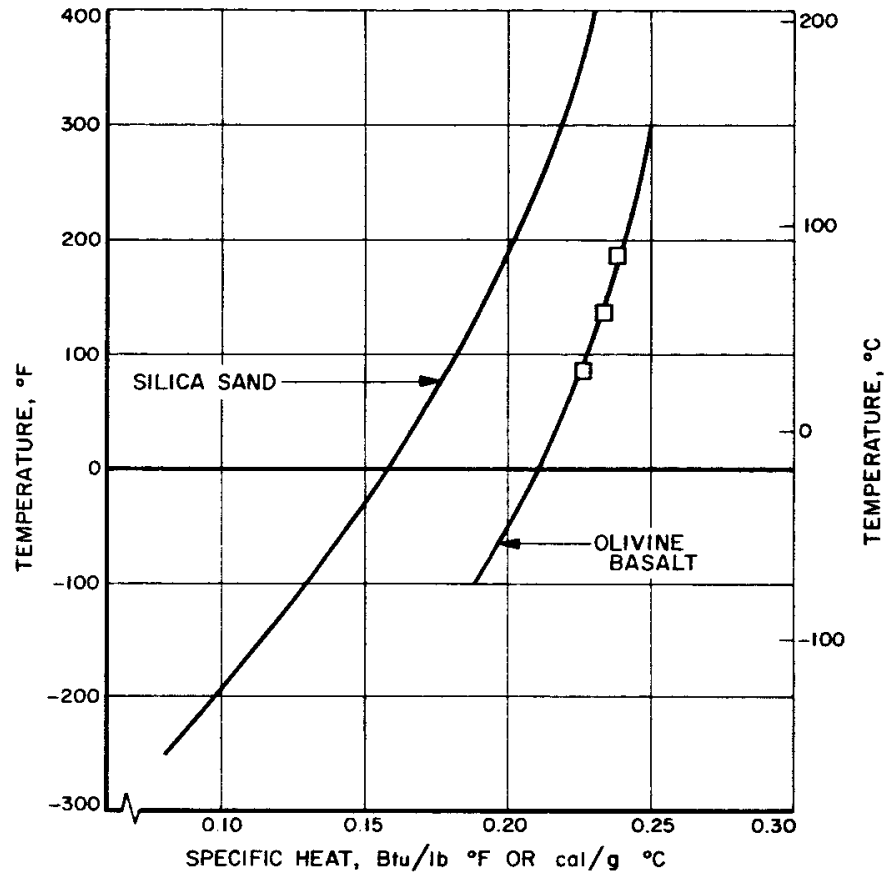

Fig. 5. Specific heat vs temperature (silica sand data from Ref. 7 and 8)

Specific-heat data for olivine basalt (or similar materials) are limited, extend over a narrow temperature range, and may be sensitive to the composition. Because

Table 3. Thermal diffusivity and conductivity of $-35+48$ mesh olivine basalta

\begin{tabular}{|c|c|c|c|c|c|c|c|c|c|c|c|}
\hline \multirow{2}{*}{$\begin{array}{l}\text { Tost } \\
\text { No. }\end{array}$} & \multirow{2}{*}{$\begin{array}{c}\text { Test } \\
\text { pressure } \\
\text { mm } \mathrm{Hg}\end{array}$} & \multicolumn{3}{|c|}{ Test temperatures, ${ }^{\circ} \mathrm{F}$} & \multicolumn{2}{|c|}{ Density } & \multirow{2}{*}{$\begin{array}{c}\text { Specific } \\
\text { heat } \\
\text { Bru/lib }{ }^{\circ} \mathrm{F} \\
\mathrm{col} / \mathrm{o}^{\circ} \mathrm{C}\end{array}$} & \multicolumn{2}{|c|}{ Thermal diffusivity } & \multicolumn{2}{|c|}{ Thermal conductivity } \\
\hline & & $T_{1}$ & $T_{2}$ & $T_{\text {avg }}$ & $\mathbf{I b} / \mathbf{f t}^{\mathbf{3}}$ & $\mathrm{g} / \mathrm{cm}^{3}$ & & $\mathrm{t}^{2} / \mathrm{hr}$ & $\mathrm{cm}^{2} / \mathrm{sec}$ & $\mathrm{Btu} / \mathrm{hr}$ ff ${ }^{\circ} \mathrm{F}$ & $\mathrm{cal} / \mathrm{sec} \mathrm{cm}{ }^{\circ} \mathrm{C}$ \\
\hline 8-29 & 760 & 69 & 160 & 115 & 85 & 1.36 & 0.230 & $5.38 \times 10^{-3}$ & $1.39 \times 10^{-3}$ & $1.05 \times 10^{-1}$ & $4.34 \times 10^{-4}$ \\
\hline $8-29 A$ & 760 & 161 & 239 & 200 & 85 & 1.36 & 0.240 & $5.12 \times 10^{-3}$ & $1.32 \times 10^{-3}$ & $1.04 \times 10^{-1}$ & $4.30 \times 10^{-4}$ \\
\hline $9-1$ & 760 & 70 & 160 & 115 & 97 & 1.56 & 0.230 & $5.21 \times 10^{-3}$ & $1.34 \times 10^{-3}$ & $1.16 \times 10^{-1}$ & $4.80 \times 10^{-4}$ \\
\hline $9 \cdot 1 \mathrm{~A}$ & 760 & 160 & 240 & 200 & 97 & 1.56 & 0.240 & $4.83 \times 10^{-3}$ & $1.24 \times 10^{-3}$ & $1.12 \times 10^{-1}$ & $4.63 \times 10^{-4}$ \\
\hline $10-10$ & 760 & 68 & -32 & 18 & 85 & 1.36 & 0.215 & $4.96 \times 10^{-3}$ & $1.28 \times 10^{-3}$ & $9.06 \times 10^{-2}$ & $3.74 \times 10^{-4}$ \\
\hline $10-10 \mathrm{~A}$ & 760 & -31 & -132 & -82 & 85 & 1.36 & 0.193 & $4.84 \times 10^{-3}$ & $1.25 \times 10^{-3}$ & $7.94 \times 10^{-2}$ & $3.28 \times 10^{-4}$ \\
\hline 10.9 & 760 & 66 & -30 & 18 & 97 & 1.56 & 0.215 & $5.26 \times 10^{-3}$ & $1.35 \times 10^{-3}$ & $1.09 \times 10^{-1}$ & $4.50 \times 10^{-4}$ \\
\hline $10.9 A$ & 760 & -31 & -132 & -82 & 97 & 1.56 & 0.193 & $5.07 \times 10^{-3}$ & $1.31 \times 10^{-3}$ & $9.49 \times 10^{-2}$ & $3.92 \times 10^{-4}$ \\
\hline $9-11$ & $5 \times 10^{-3}$ & 70 & 162 & 116 & 97 & 1.56 & 0.230 & $1.32 \times 10^{-4}$ & $3.40 \times 10^{-5}$ & $2.94 \times 10^{-3}$ & $1.21 \times 10^{-5}$ \\
\hline $9-12$ & $5 \times 10^{-3}$ & 154 & 240 & 197 & 97 & 1.56 & 0.240 & $1.76 \times 10^{-4}$ & $4.54 \times 10^{-5}$ & $4.10 \times 10^{-3}$ & $1.69 \times 10^{-5}$ \\
\hline $9-5$ & $5 \times 10^{-6}$ & 69 & 161 & 115 & 97 & 1.56 & 0.230 & $1.15 \times 10^{-4}$ & $2.96 \times 10^{-5}$ & $2.56 \times 10^{-3}$ & $1.06 \times 10^{-5}$ \\
\hline $9-6$ & $5 \times 10^{-6}$ & 148 & 238 & 193 & 97 & 1.56 & 0.240 & $1.36 \times 10^{-4}$ & $3.50 \times 10^{-5}$ & $3.16 \times 10^{-3}$ & $1.30 \times 10^{-5}$ \\
\hline $11-7$ & $5 \times 10^{-6}$ & 73 & -32 & 20 & 97 & 1.56 & 0.215 & $1.11 \times 10^{-4}$ & $2.86 \times 10^{-5}$ & $2.31 \times 10^{-3}$ & $9.55 \times 10^{-6}$ \\
\hline 11.8 & $5 \times 10^{-6}$ & -14 & -128 & -71 & 97 & 1.56 & 0.195 & $1.52 \times 10^{-4}$ & $3.92 \times 10^{-5}$ & $2.87 \times 10^{-3}$ & $1.18 \times 10^{-5}$ \\
\hline
\end{tabular}


of this lack of reliable data, determinations of the specific heat of the olivine basalt used were made between room temperature and 100,200 , and $300^{\circ} \mathrm{F}$. These determinations were made using a calorimetric method in accordance with American Society for Testing and Materials Standard Procedure C351-61. These measured specific heat values are plotted in Fig. 5. It has been reported (Ref. 9) that within limits, the variation of specific heat with temperature is similar for various types of crushed rock. With this in mind, the curve through the measured points for the olivine basalt (Fig. 5) was extrapolated to give specific-heat values over the temperature range used in this investigation. Thermal conductivity values listed in Tables 2 through 5 were calculated from the average thermal diffusivity values determined graphically (Fig. 4) and the measured densities and specific heat values (Fig. 5).

For a few of the tests, thermal conductivity was also calculated from the experimental data using a digital computer. The computer solution avoids the assumption made in the graphical method that conductivity and specific heat are constant over the temperature range of a single test. Values obtained with the computer were in agreement with those obtained graphically.

In order to facilitate analysis of the test data, the diffusivity and conductivity values are shown graphically in Fig. 6 through 10, inclusive. The last plot (Fig. 10) shows the thermal diffusivity and conductivity for the three lots of basalt measured at approximately the same packing density. The effect of particle size may be readily evaluated.

An error analysis of the measuring and calculation procedure was also made (see Appendix). The chief sources of error were found to be heat flow through the ends of the test specimen, lack of complete temperature uniformity at the start of a test, and uncertainties in the specific heat. Less important sources were temperature, time, and position measurements, heat flow along thermocouples and bottom closure, and variation of thermal properties with temperature during the course of a test. The estimated error from all of these sources in each value of diffusivity is about $10 \%$, in each value of conductivity about $15 \%$.

Table 4. Thermal diffusivity and conductivity of -35 mesh olivine basalta

\begin{tabular}{|c|c|c|c|c|c|c|c|c|c|c|c|}
\hline \multirow{2}{*}{$\begin{array}{l}\text { Test } \\
\text { No. }\end{array}$} & \multirow{2}{*}{$\begin{array}{c}\text { Test } \\
\text { pressure } \\
\text { mm Hg }\end{array}$} & \multicolumn{3}{|c|}{ Test temperatures, ${ }^{\circ} \mathrm{F}$} & \multicolumn{2}{|c|}{ Density } & \multirow{2}{*}{$\begin{array}{l}\text { Specific } \\
\text { heof } \\
\text { Btu//b }{ }^{\circ} \mathrm{F} \\
\mathrm{cal} / \mathrm{g}^{\circ} \mathrm{C}\end{array}$} & \multicolumn{2}{|c|}{ Thermal diffusivity } & \multicolumn{2}{|c|}{ Thermal conduetivily } \\
\hline & & $T_{1}$ & $T_{2}$ & $T_{\text {avg }}$ & $\mathbf{I b} / \mathrm{ft}^{\mathbf{3}}$ & $\mathrm{g} / \mathrm{cm}^{3}$ & & $\mathrm{Hr}^{2} / \mathrm{hr}$ & $\mathrm{cm}^{2} / \mathrm{sec}$ & Bro/hr fi' $F$ & $\mathrm{col} / \mathrm{sec} \mathrm{cm}^{\circ} \mathrm{C}$ \\
\hline $4-25$ & 760 & 73 & 124 & 99 & 93 & 1.49 & 0.227 & & & & \\
\hline $4-25 A$ & 760 & 122 & 176 & 149 & 93 & 1.49 & 0.234 & $4.16 \times 10^{-3}$ & $1.07 \times 10^{-3}$ & $9.05 \times 10^{-2}$ & $3.74 \times 10^{-4}$ \\
\hline $4-25 B$ & 760 & 174 & 228 & 201 & 93 & 1.49 & 0.240 & $5.91 \times 10^{-3}$ & $1.53 \times 10^{-3}$ & $1.32 \times 10^{-1}$ & $5.45 \times 10^{-4}$ \\
\hline $8-28$ & 760 & 89 & 161 & 125 & 113 & 1.65 & 0.231 & $6.12 \times 10^{-3}$ & $1.58 \times 10^{-3}$ & $1.59 \times 10^{-1}$ & $6.57 \times 10^{-4}$ \\
\hline $8-28 \mathrm{~A}$ & 760 & 162 & 242 & 202 & 113 & 1.65 & 0.240 & $6.45 \times 10^{-3}$ & $1.66 \times 10^{-3}$ & $1.75 \times 10^{-1}$ & $7.23 \times 10^{-4}$ \\
\hline 4.27 & 760 & 65 & 23 & 44 & 93 & 1.49 & 0.219 & $6.97 \times 10^{-3}$ & $1.80 \times 10^{-3}$ & $1.42 \times 10^{-1}$ & $5.87 \times 10^{-4}$ \\
\hline $4.27 \mathrm{~A}$ & 760 & 12 & -32 & -10 & 93 & 1.49 & 0.209 & $7.55 \times 10^{-3}$ & $1.95 \times 10^{-3}$ & $1.47 \times 10^{-1}$ & $6.07 \times 10^{-4}$ \\
\hline $10-13$ & 760 & 73 & -31 & 21 & 93 & 1.49 & 0.215 & $4.76 \times 10^{-3}$ & $1.23 \times 10^{-3}$ & $9.52 \times 10^{-2}$ & $3.94 \times 10^{-4}$ \\
\hline $10-13 A$ & 760 & -34 & -131 & -83 & 93 & 1.49 & 0.193 & $4.57 \times 10^{-3}$ & $1.18 \times 10^{-3}$ & $8.20 \times 10^{-2}$ & $3.39 \times 10^{-4}$ \\
\hline $10-16$ & 760 & 70 & -31 & 19 & 122 & 1.95 & 0.214 & $5.67 \times 10^{-3}$ & $1.46 \times 10^{-3}$ & $1.48 \times 10^{-1}$ & $6.12 \times 10^{-4}$ \\
\hline $10-16 \mathrm{~A}$ & 760 & -39 & -132 & -86 & 122 & 1.95 & 0.192 & $5.50 \times 10^{-3}$ & $1.42 \times 10^{-3}$ & $1.29 \times 10^{-1}$ & $5.33 \times 10^{-4}$ \\
\hline 7.11 & $5 \times 10^{-6}$ & 73 & 159 & 116 & 93 & 1.49 & 0.230 & $6.49 \times 10^{-5}$ & $1.67 \times 10^{-5}$ & $1.39 \times 10^{-3}$ & $5.75 \times 10^{-6}$ \\
\hline 7.13 & $5 \times 10^{-6}$ & 146 & 240 & 193 & 93 & 1.49 & 0.239 & $7.63 \times 10^{-5}$ & $1.97 \times 10^{-5}$ & $1.70 \times 10^{-3}$ & $7.03 \times 10^{-0}$ \\
\hline 7.17 & $5 \times 10^{-6}$ & 71 & 167 & 119 & 113 & 1.65 & 0.230 & $9.93 \times 10^{-5}$ & $2.56 \times 10^{-5}$ & $2.58 \times 10^{-3}$ & $1.07 \times 10^{-5}$ \\
\hline $7-19$ & $5 \times 10^{-6}$ & 160 & 241 & 201 & 113 & 1.65 & 0.240 & $7.77 \times 10^{-5}$ & $2.00 \times 10^{-5}$ & $2.10 \times 10^{-3}$ & $8.68 \times 10^{-6}$ \\
\hline 7.26 & $5 \times 10^{-6}$ & 71 & 156 & 114 & 113 & 1.65 & 0.229 & $8.92 \times 10^{-5}$ & $2.30 \times 10^{-5}$ & $2.31 \times 10^{-3}$ & $9.55 \times 10^{-6}$ \\
\hline 7.27 & $5 \times 10^{-6}$ & 140 & 236 & 188 & 113 & 1.65 & 0.239 & $9.51 \times 10^{-5}$ & $2.45 \times 10^{-5}$ & $2.57 \times 10^{-3}$ & $1.06 \times 10^{-5}$ \\
\hline $10-24$ & $5 \times 10^{-6}$ & 66 & -30 & 18 & 93 & 1.49 & 0.214 & $5.00 \times 10^{-5}$ & $1.29 \times 10^{-5}$ & $9.95 \times 10^{-4}$ & $4.11 \times 10^{-6}$ \\
\hline 11.1 & $5 \times 10^{-6}$ & 75 & -124 & -24 & 109 & 1.75 & 0.206 & $4.56 \times 10^{-5}$ & $1.17 \times 10^{-5}$ & $1.02 \times 10^{-3}$ & $4.22 \times 10^{-6}$ \\
\hline $12-18$ & $5 \times 10^{-6}$ & 72 & -32 & 20 & 98 & 1.57 & 0.215 & $5.00 \times 10^{-5}$ & $1.29 \times 10^{-5}$ & $1.05 \times 10^{-3}$ & $4.34 \times 10^{-6}$ \\
\hline $12-21$ & $5 \times 10^{-6}$ & -15 & -120 & -68 & 98 & 1.57 & 0.196 & $4.71 \times 10^{-5}$ & $1.22 \times 10^{-5}$ & $9.05 \times 10^{-4}$ & $3.74 \times 10^{-6}$ \\
\hline
\end{tabular}



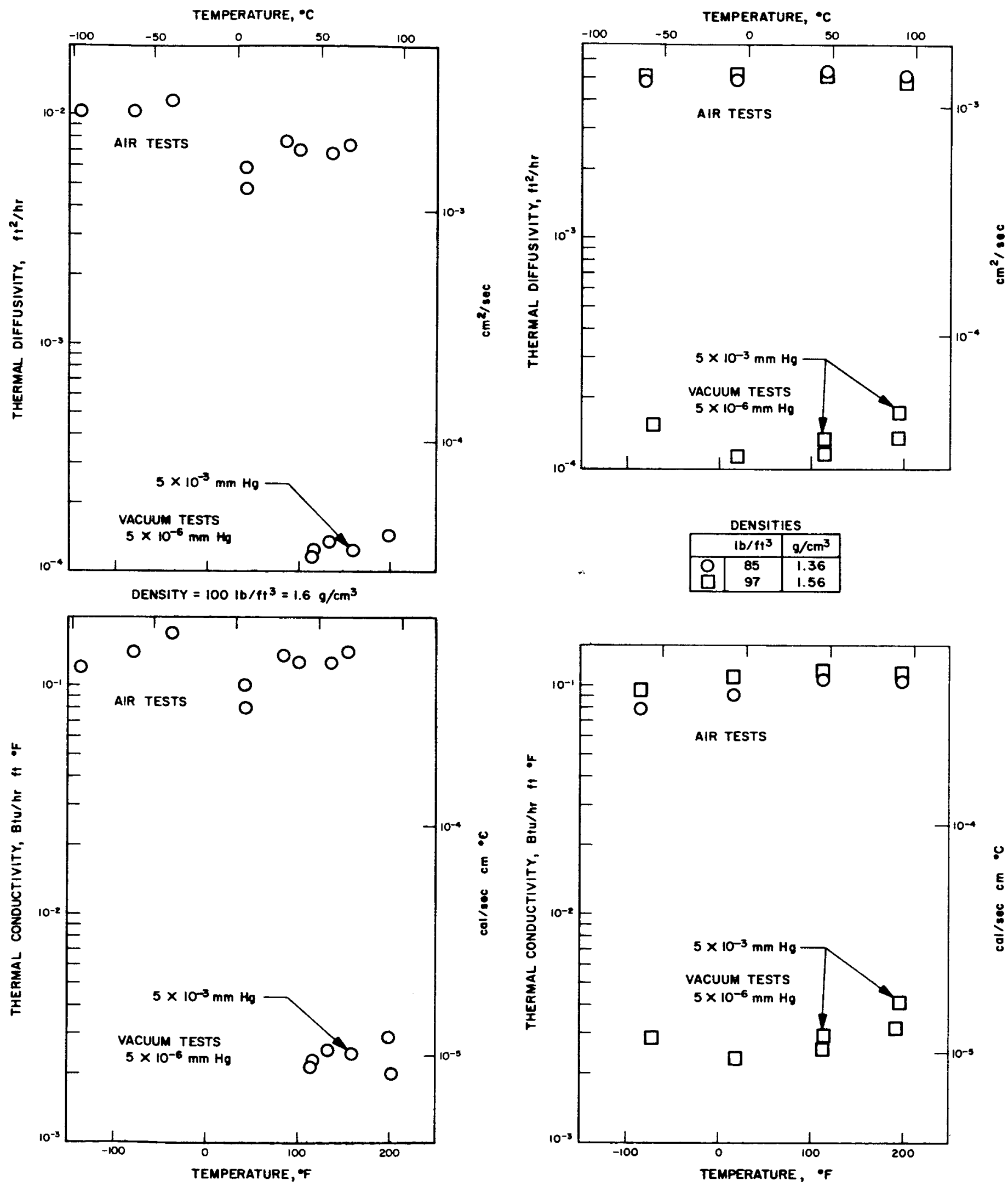

Fig. 6. Thermal diffusivity and conductivity vs temperature of $99 \%$ silica sand

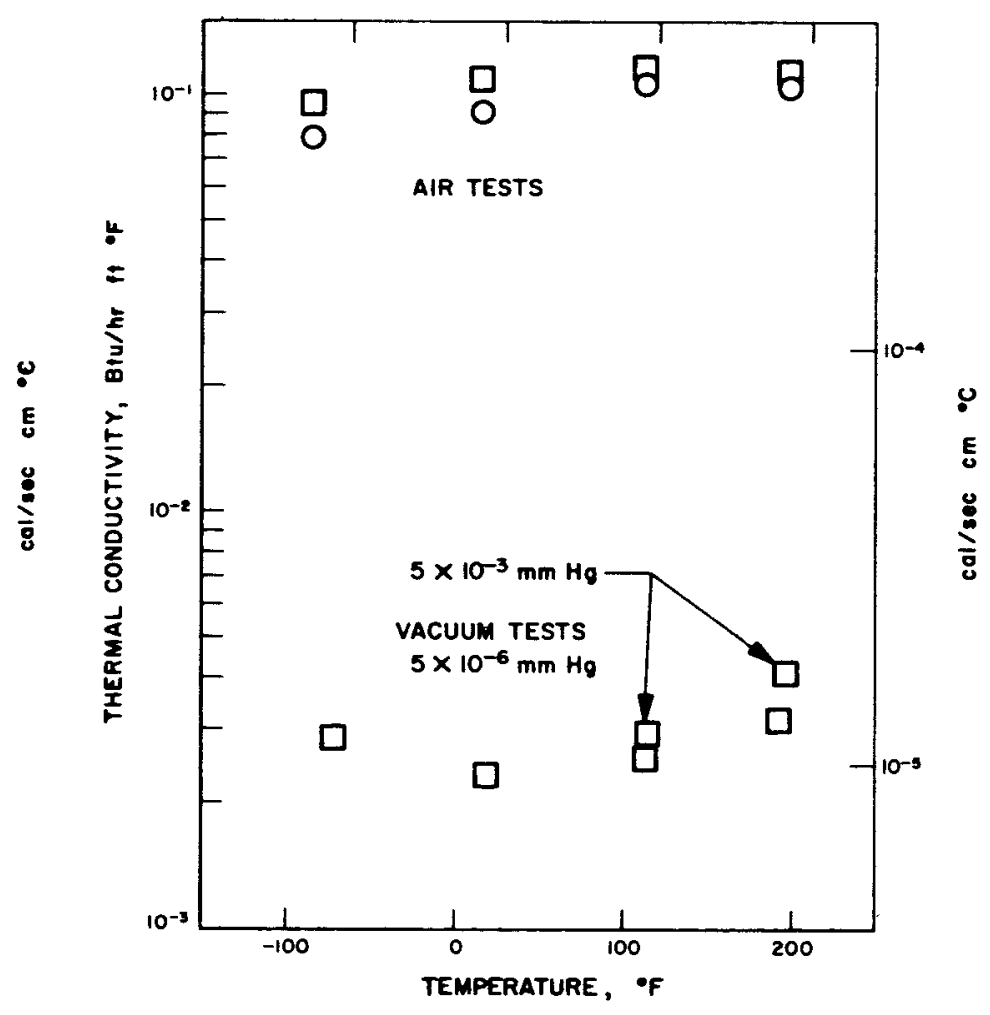

Fig. 7. Thermal diffusivity and conductivity vs temperafure of $-35+48$ mesh olivine basalt 

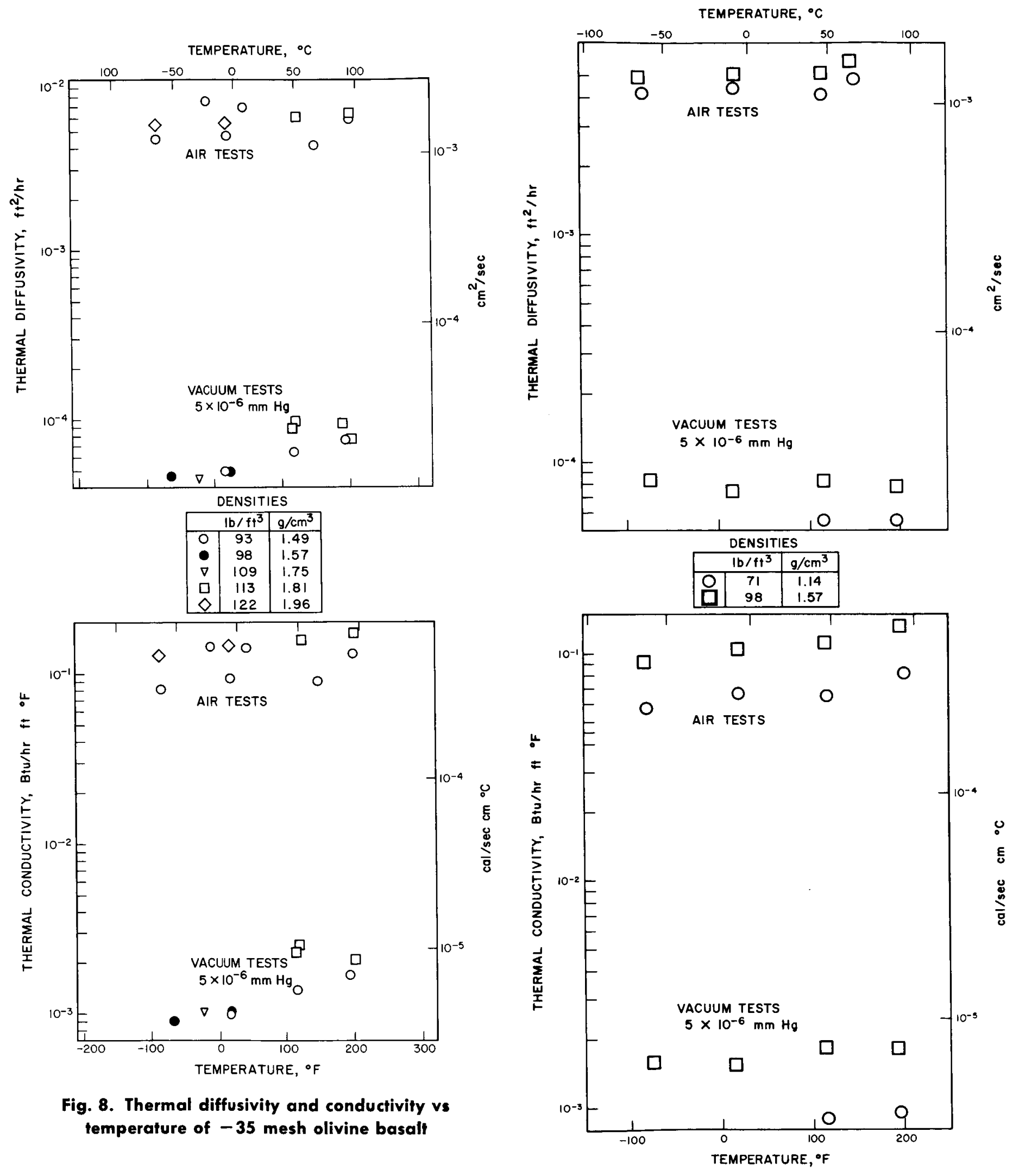

Fig. 8. Thermal diffusivity and conductivity vs temperafure of -35 mesh olivine basalf

Fig. 9. Thermal diffusivity and conductivity vs temperature of -150 mesh olivine basalt 

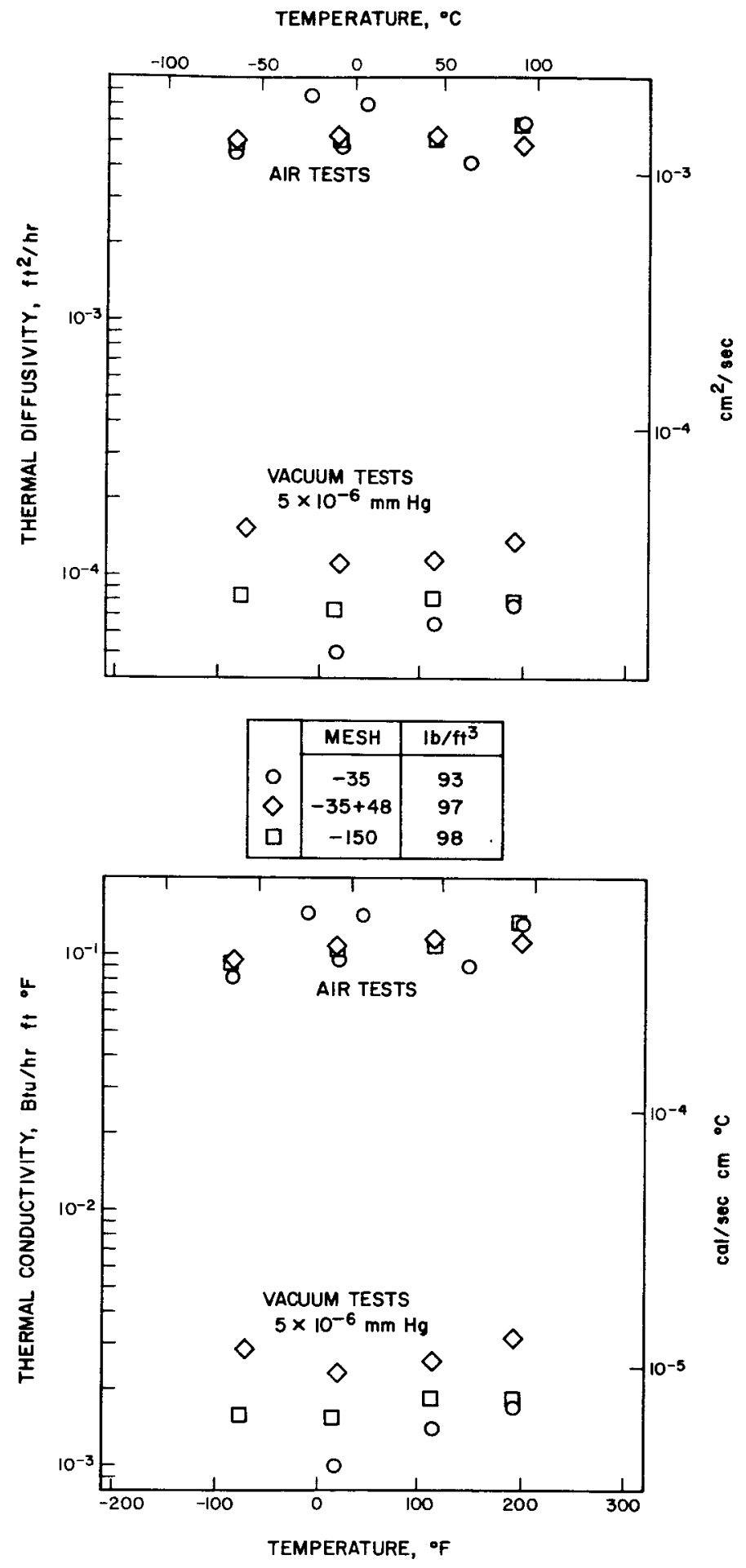

Fig. 10. Thermal diffusivity and conductivity vs temperature of olivine basalt 


\begin{tabular}{|c|c|c|c|}
\hline \multirow{2}{*}{ 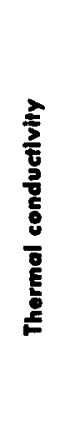 } & $\begin{array}{l}u \\
0 \\
\mathbf{E} \\
\mathbf{g} \\
\bar{g} \\
\mathrm{~g}\end{array}$ & 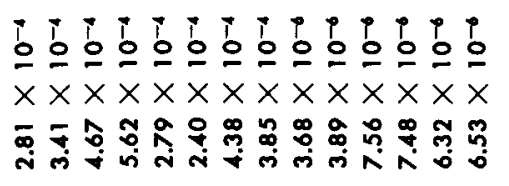 & \\
\hline & 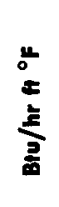 & 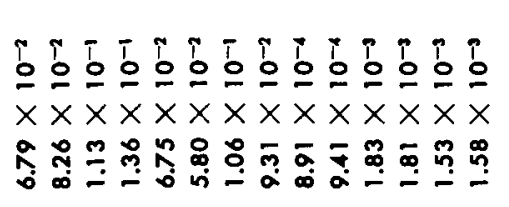 & \\
\hline \multirow{2}{*}{ 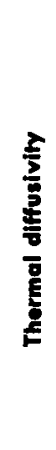 } & $\stackrel{\Xi}{\tilde{E}}$ & 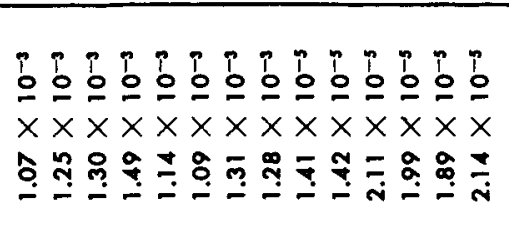 & \\
\hline & $\underset{z}{\xi}$ & 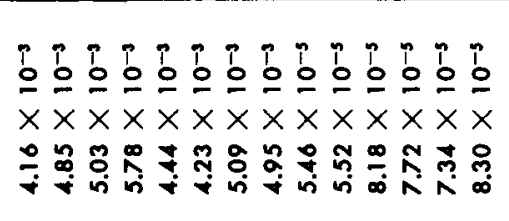 & \\
\hline \multicolumn{2}{|c|}{ 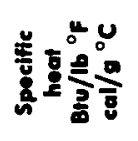 } & 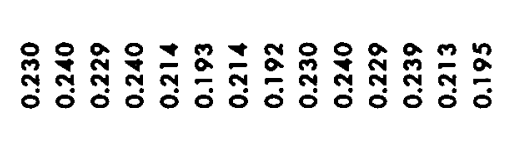 & \\
\hline \multirow{2}{*}{$\stackrel{z}{\underline{g}}$} & $\stackrel{E}{E}$ & 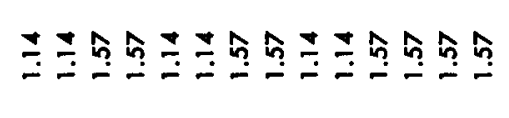 & \\
\hline & $\underline{z}$ & 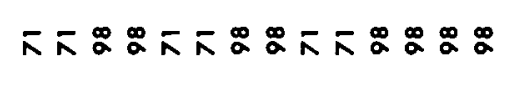 & \\
\hline \multirow{3}{*}{ 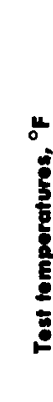 } & 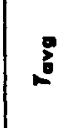 & 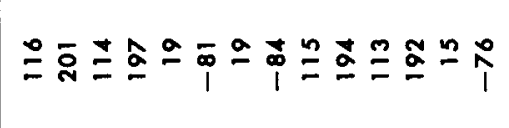 & \\
\hline & $\approx$ & 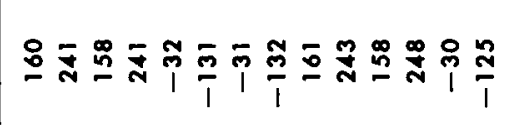 & \\
\hline & $=$ & 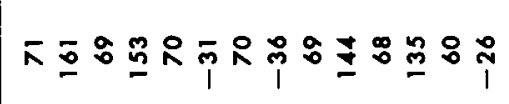 & \\
\hline \multicolumn{2}{|c|}{ 部量 } & 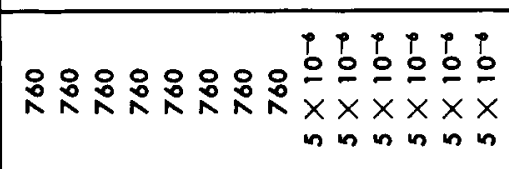 & 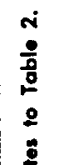 \\
\hline \multicolumn{2}{|c|}{ 醇 } & 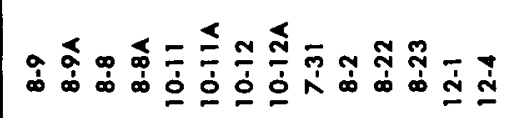 & $\stackrel{5}{\vdots}$ \\
\hline
\end{tabular}




\section{DISCUSSION OF RESULTS}

The thermal properties of silica sand determined in air (Table 2 and Fig. 6) are in good agreement with literature values (Ref. 10). At reduced pressures $\left(10^{-3}\right.$ and $10^{-6} \mathrm{~mm} \mathrm{Hg}$ range), the measured diffusivities and conductivities were roughly 100 times lower. There were no comparable thermal property data at these vacuum levels found in the literature. Tests in poorer vacuum environments are reported (Ref. 11), and it is interesting to note that the thermal conductivity of sand at $10^{-1}$ and $10^{-2}$ $\mathrm{mm} \mathrm{Hg}$ is not greatly different from the values obtained in the present investigation at $10^{-3}$ and $10^{-6} \mathrm{~mm} \mathrm{Hg}$. The major change in thermal properties occurs when the interstitial air pressure drops from atmospheric down to about $10^{-2} \mathrm{~mm} \mathrm{Hg}$; beyond this, the thermal diffusivity and conductivity are relatively constant.

The results of the tests on the olivine basalt are given in Tables 3 through 5 and Fig. 7 through 10. Again the thermal diffusivity and conductivity as measured in vacuum were approximately 100 times lower than the values measured in air. These data also show that the effects of vacuum are very much greater than the effects of temperature, packing density, or particle size of the test material.

It is interesting to note that the values of thermal conductivity obtained for the olivine basalt in vacuum are in good agreement with the value $\left(3\right.$ to $10 \times 10^{-6} \mathrm{cal} / \mathrm{cm}$ sec ${ }^{\circ} \mathrm{C}$ ) of thermal conductivity calculated for the lunar surface from measurements made during a lunar eclipse (Ref. 1, 2).

The effects of the vacuum may be explained by considering the thermal conduction process. For the tests in air, the conduction is through the particles of basalt and through the air which fills the voids. For the tests in vacuum, there is conduction through the basalt particles but very little through the evacuated voids. Thus, a major portion of the thermal energy must be transferred through the voids by radiation, which is very low at the temperature used in this study. Therefore, the thermal conductivity as measured in vacuum would be lower than the value measured in air.

The degree of vacuum in which the measurement was made would affect the amount of energy transferred by conduction through the voids, but this would be small except for very poor vacuums. While the equipment used was not particularly suited to running tests at various levels of vacuum, it was possible to run some tests at two levels. The results of these (Tables 2 and 3 ) show that increasing the pressure from $10^{-6}$ to $10^{-3} \mathrm{~mm} \mathrm{Hg}$ increased the conductivity by a small amount. It would therefore seem reasonable to assume that at pressures below $10^{-6}$ $\mathrm{mm} \mathrm{Hg}$, the thermal conductivity will not be markedly affected by the pressure.

The effect of test temperature on the values obtained during the tests in air is small (Fig. 7-10). This is what would be expected, as the thermal conductivity of the basalt particles and of the air in the voids between the particles would not change markedly over the range of temperatures studied. Since the test temperature would affect the radiation through the evacuated voids, it should affect the thermal conductivity as measured in vacuum. The lower the test temperature, the lower the conductivity would be. Although the test data are limited, they do seem to show some effect of temperature (Fig. 7-10).

For a given particle size distribution, the higher the packing density, the lower the percentage of voids and the more continuous the conduction path. Thus, it would be expected that the thermal conductivity in both air and vacuum should increase with an increase in packing density. Again, the available data are limited; however, they do indicate this behavior.

The effects of the particle size distribution are not as clearly understood. The data available from the tests run during this investigation are shown in Fig. 10. From these, it would appear that the particle size distribution has very little effect upon the thermal conductivity as measured in air but does have an effect on the value measured in vacuum: material with a sharp and coarse distribution $(-35+48$ mesh) has a higher conductivity than the material with a broader distribution of particle sizes. Because of other factors which could also be affecting these data, they should not be considered as conclusive. 


\section{CONCLUSIONS}

From the results obtained during this investigation, the following conclusion may be stated:

1. The thermal conductivity of the crushed olivine basalt used was approximately 100 times lower when measured in vacuum than when measured in air at atmospheric pressure. The value measured in vacuum is in good agreement with the value for the lunar surface calculated from astronomical data.

2. Increasing the pressure from $5 \times 10^{-6}$ to $5 \times 10^{-3}$ $\mathrm{mm} \mathrm{Hg}$ had no marked effect on the thermal conductivity of the crushed basalt.

3. For the $-\mathbf{1 5 0}$ mesh material the thermal conductivity in air and in vacuum was increased approxi- mately $60 \%$ at all test temperatures when the packing density was increased from 1.14 to 1.57 $\mathrm{g} / \mathrm{cm}^{3}$.

4. Decreasing the average temperature of the crushed basalt specimen from 100 to $-70^{\circ} \mathrm{C}$ caused a decrease in the thermal conductivity.

5. For the particular distributions used, the particle size had a greater effect on the values of thermal conductivity measured in vacuum than on the values measured in air.

6. The thermal conductivities of the olivine basalt and the silica sand are not markedly different. From this, it is concluded that composition of the crushed material has only a minor effect on its thermal conductivity. 


\section{APPENDIX}

Error Analysis

\section{SUMMARY}

An analysis was made of the various sources which introduce errors into the calculated values of thermal diffusivity and conductivity. This indicated that the over-all accuracy of the individual diffusivity values was probably about $10 \%$ and of the conductivity values calculated manually about $15 \%$. For conductivity values calculated by machine, the accuracy was probably about $10 \%$.

Important in the error analysis is the fractional temperature

$$
U=\frac{T_{2}-T}{T_{2}-T_{1}}
$$

where $T=$ temperature at center or midradius and $T_{1}$ and $T_{2}$ are as defined in Table 2 . To keep the errors in the calculated properties low, only values of $U$ between 0.2 and 0.5 were used for manual calculations and only values between 0.2 and 0.9 for machine calculations.

The amounts of error believed to be contributed by various sources are tabulated in Table A-1. These numbers are combined by taking the square root of the sum of their squares.

\section{DETAILS}

\section{A. Errors Arising From Time Measurements}

Diffusivities $(\alpha)$ are calculated from the quantity $\alpha t / s^{2}$ of Fig. 4, where $t=$ time from start of test and $s=$ cylinder radius. An error in time measurements, $\Delta t$, then produces a corresponding error in diffusivity, $\Delta \alpha$, given by

$$
\frac{\Delta \alpha}{\alpha}=\frac{\Delta t}{t}
$$

The accuracy of time measurements was about $10 \mathrm{sec}$. The time of run $t$ was typically 16,24 , and $30 \mathrm{~min}$ for tests in air at $U=0.5,0.2$, and 0.1 , respectively; in vacuum, corresponding typical times were 12,18 , and $25 \mathrm{hr}$. At $U=0.9$, in air, a typical center time was 12 min, a midradius time 6 min; in vacuum, a typical time was $4 \frac{1}{2} \mathrm{hr}$. Substituting these values in Eq. (A-2) gave $100 \Delta \alpha / \alpha$, the percent error in $\alpha$ listed in Table A-1. by

As the thermal conductivity $k$ is related to diffusivity

$$
\alpha=\frac{k}{\rho c}
$$

where $\rho=$ density of sample and $c=$ specific heat.

$$
\frac{\Delta k}{k}=\frac{\Delta \alpha}{\alpha}
$$

or the percent error in conductivity is equal to the percent error in diffusivity.

In both manual and machine computations, the values obtained for $k$ and $\alpha$ are based on several experimental measurements: temperature readings at several times and at both center and midradius. Because of the averaging involved in this, the error in the resulting thermal quantity will be less than the error in an individual reading by a factor of $\mathrm{I} \sqrt{n}$, where $n=$ number of measurements.

\section{B. Errors Arising From Temperafure Measurements}

The slope of the curves (Fig. 4) indicates that an error in fractional temperature, $\Delta U$, produces a corresponding 


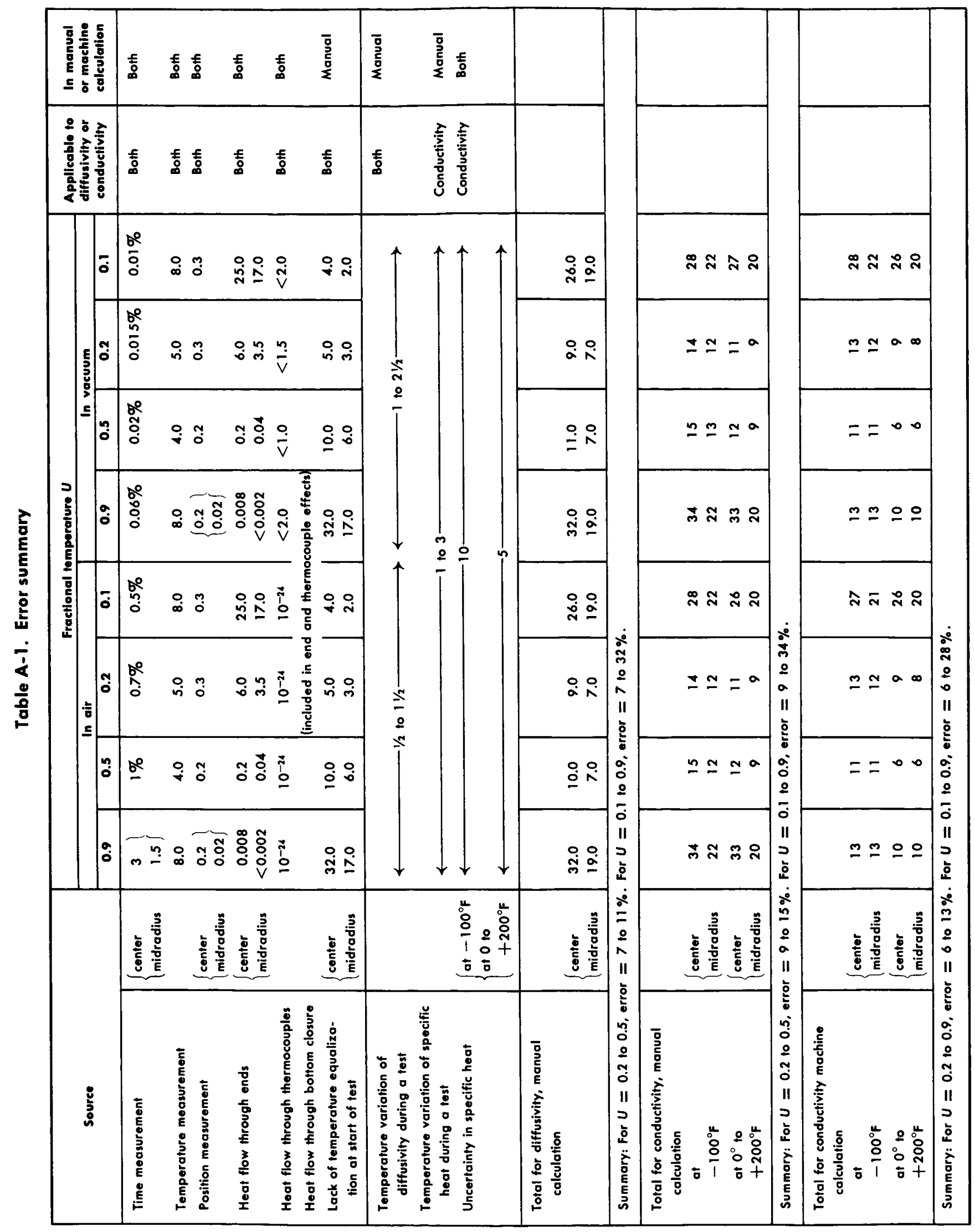


fractional error in $\alpha t / s^{2}$, which is given by $\left[-\Delta\left(\alpha t / s^{2}\right) /\right.$ $\left.\left(\alpha t / s^{2}\right)\right] / \Delta U=4.1,2.6,2.1,2.7$, and 4.2 for $U=0.9,0.8$, $0.5,0.2$, and 0.1 , respectively. As

$$
\frac{\Delta \alpha}{\alpha}=\frac{\Delta\left(a t / s^{2}\right)}{\alpha t / s^{2}}
$$

these ratios give the fractional error in diffusivity and, by Eq. (A-4), in conductivity, resulting from an error in temperature measurement. Temperature differences were measured to $1^{\circ} \mathrm{F}$; this includes errors in thermocouples and recorder calibration. The difference $T_{2}-T$ was typically $50^{\circ} \mathrm{F}$, so $\Delta U$, by Eq. (A-1), was about $2 \%$. Corresponding errors in $\alpha$ are listed in Table A-l. Again, these estimates could be reduced by $1 / \sqrt{n}$.

\section{Errors Arising From Position Measurements}

Errors in radial dimensions $\Delta s$, such as in the thermocouple positions, contribute to errors in $\alpha$ in two ways. First, they mean that the applicable curve (Fig. 4) is not that for center or midradius but a curve for some slightly different position. The Figure suggests that the corresponding $(\Delta \alpha / \alpha) /(\Delta s / s)=\left[\Delta\left(\alpha t / s^{2}\right) /\left(\alpha t / s^{2}\right)\right] /$ $(\Delta s / s)$ is about $-1,-0.6$, and -0.4 at $U=0.5,0.2$, and 0.1 , respectively. At $U=0.9$, it is about -1 at center and -2 at midradius. Second, for any given value of $a t / s^{2}$,

$$
\frac{\Delta \alpha}{\alpha}=\frac{2 \Delta s}{s}
$$

Summing these effects algebraically, one finds that for midradius readings at $U=0.9$, the two error contributions cancel to a first approximation. For center readings at $U=0.9,(\Delta \alpha / \alpha) /(\Delta s / s)$ is about 1 ; for readings at $U=$ $0.5,0.2$, and 0.1 , this ratio is, respectively, $1,1.4$, and 1.6.

The thermocouple positions are believed to be accurate to $\mathbf{0 . 0 0 2}$ in.; the cylinder dimensions are more accurate. Dimension $\Delta s$ may then be taken as 0.002 in.; the nominal radius $s=1 \mathrm{in}$. The value $\Delta s / s=0.002$ was used as the basis for the $100 \Delta \alpha / \alpha$ values of Table A-1.

\section{Errors Arising From Heaf Flow Through Ends}

The equations and curves used in calculating thermal diffusivity and conductivity from the experimental data assume that the sample cylinder may be considered infinitely long: that axial heat transfer does not affect the temperatures at the midlength. The error due to the finite length of the cylinder, which permits heat flow through the ends, can be estimated by using the superposition principle. One may consider the resulting change in temperature as that occurring in a superposed infinite flat plate placed perpendicular to the cylinder axis, with its midplane at the cylinder midlength and its surfaces at the cylinder ends. End conditions on the cylinder correspond to surface conditions on the plate. Tables are available (Ref.6) showing the variations of the fractional temperature at the plate midplane, $U_{\mathrm{plate}}$, as a function of the quantity $\alpha t / s_{\text {plate, }}^{2}$ for an abrupt change of temperature at the plate surfaces. Here, $s$ plate is half the plate thickness. For the dimensions used in the experiment,

$$
s_{\text {plate }}=2 \text { in. }=2 s
$$

At any time, then,

$$
\frac{\alpha t}{s_{\text {Plate }}^{2}}=\frac{1 / 4 \alpha t}{s^{2}}
$$

From Fig. 4, one may read the values of $\alpha t / s^{2}$ corresponding to various values of $U$ at cylinder center and midradius and, by Eq. (A-8), get the corresponding values of $\alpha t / s^{2}$ plate. Reference 6 then gives corresponding values of $U_{\text {plate }}$. The quantity $1-U_{\text {plate }}$ may be considered as the change in $U$ that would result if the cylinder ends were at all times at the temperature of the cylindrical surface.

In practice, it seems likely that the end temperature during a test remained closer to the initial temperature than to the cylindrical surface temperature; tests were always made by stepping the cylindrical surface temperature away from room temperature, and the ends could "see" (exchange radiation with) mostly objects near room temperature. The fractional temperature difference between end and midlength would then be near zero at the start of a test and $1-U$ when a reading was taken, or $(1-U) / 2$ on the average. For ends at the cylindrical surface temperature, this difference would be 1 at the start and $U$ when a reading was taken, or $(1+U) / 2$ on the average. The value of $1-U_{\text {plate }}$, calculated as above, was therefore multiplied by $(1-U) /(1+U)$ to give an estimate of the error in $U$.

The values obtained for $\Delta U=\left(1-U_{\text {plate }}\right)(1-U) /$ $(I+U)$ were $0.00002,0.001,0.06$, and 0.023 at center and $0.000005,0.0002,0.04$, and 0.013 at midradius for $U=$ $0.9,0.5,0.2$, and 0.1 , respectively. These values were multiplied by the ratios of $-(\Delta \alpha / \alpha) / \Delta U$ stated in Section II-B to give fractional errors in diffusivity; the errors are listed, as percents, in Table A-1.

\section{E. Errors Arising from Heaf Flow Through Thermocouples}

Heat flow along the thermocouple wires will change the temperature at the junctions and introduce a tem- 
perature error. Jakob (Ref. 5) gives a solution for the steady-state temperature distribution of a wire along the axis of a finite insulating cylinder whose cylindrical surface is at constant temperature. Inserting the values pertinent to this experiment, the solution is

$$
T_{L}-T_{0}=2\left(T_{0}-T_{2}\right) \sinh ^{2}\left[\frac{1}{2} s_{\text {plate }} \sqrt{\frac{2 k}{k_{v o}} r^{2} \ln \frac{R}{r}}\right]
$$

where

$$
\begin{aligned}
T_{L} & =\text { temperature of wire at end of cylinder } \\
T_{0} & =\text { temperature of wire at midlength of cylinder } \\
s_{\mathrm{plate}} & =\text { half the axial length }=2 \mathrm{in} . \\
k_{\omega} & =\text { thermal conductivity of wire } \simeq 14 \mathrm{Btu} / \mathrm{hr} \mathrm{ft} .{ }^{\circ} \mathrm{F} \\
r & =\text { radius of wire }=0.0015 \mathrm{in} . \\
R & =\text { radius of assumed insulating cylinder } \\
& =1 \mathrm{in} . \text { for center thermocouple } \\
& =1 / 2 \mathrm{in} . \text { for midradius thermocouple }
\end{aligned}
$$

The thermal conductivity $k$ of the test material was taken as $10^{-1} \mathrm{Btu} / \mathrm{hr} \mathrm{ft}{ }^{\circ} \mathrm{F}$ in air and $(0.9$ to 3$) \times 10^{-3}$ $\mathrm{Btu} / \mathrm{hr} \mathrm{ft}{ }^{\circ} \mathrm{F}$ in vacuum (Tables 2-5); $T_{L}$ was taken as the initial temperature of the test, $T_{1}$.

Solving for the relative temperature change at the midlength produced by the couple, one finds

$$
\begin{aligned}
\Delta U & =\frac{T_{2}-T_{0}}{T_{2}-T_{1}}=\frac{T_{2}-T_{0}}{\left(T_{2}-T_{0}\right)-\left(T_{2}-T_{0}\right)} \\
& =\frac{1}{1+\frac{T_{\mathrm{L}}-T_{0}}{T_{0}-T_{2}}} \\
& =\frac{1}{1+2 \sinh ^{2}\left[\frac{1}{2} s \text { plate } \sqrt{\frac{2 k}{k_{w}} r^{2} \ln \frac{R}{r}}\right]}
\end{aligned}
$$

In air, this gives $\Delta U=2 \times 10^{-27}$ at center and $5 \times 10^{-29}$ at midradius. In vacuum, the corresponding center value is $5 \times 10^{-3}$ or $4 \times 10^{-5}$, depending on whether test material conductivity is taken as $0.9 \times 10^{-3}$ or $3 \times 10^{-3}$ $\mathrm{Btu} / \mathrm{hr} \mathrm{ft}{ }^{\circ} \mathrm{F}$; the midradius value is $4 \times 10^{-3}$ or $2 \times 10^{-5}$. Multiplying by the ratios of $-100(\Delta \alpha / \alpha) / \Delta U$ from Section II-B, percentage errors in diffusivity and conductivity are obtained. The errors given in Table A-1 correspond to the largest values so obtained, and are thus conservative. Moreover, the calculation of temperature differences due to the thermocouples is based on steady-state conditions; these are not attained during a test. The transient temperature differences will be smaller, so the errors quoted are again conservative.

It may be noted that because $\sinh x$ (Eq. A-10) may vary rapidly with $x$, the errors arising from heat flow in the thermocouples are very sensitive to experimental conditions. For example, if the thermocouple wires had been 0.012 instead of $0.003 \mathrm{in}$. in diameter, the diffusivity and conductivity determinations could be in error by a factor of 2 .

\section{F. Errors Arising From Heat Flow Through the Bottom Closure}

Heat flow through the bottom closure affects the calculated values of the thermal properties only insofar as it introduces axial heat flow through the ends of thermocouples and dust. Errors arising from such axial flow have been estimated above.

\section{G. Errors Arising From Lack of Temperafure Equalization at Start of Test}

In a series of tests on a given specimen, complete equalization of temperature was not always attained after one step in copper cylinder temperature and before a second step. This would not affect conductivity values calculated by digital computer, as the measured radial distribution of temperature at the start of the test was inserted into the computer. For manual calculations, however, uniform temperature at the start of each test was assumed. In the worst cases, the initial difference between center thermocouple and copper cylinder thermocouple amounted to about $10^{\circ} \mathrm{F}$, between midradius thermocouple and copper cylinder thermocouple to about $6^{\circ} \mathrm{F}$. For $100^{\circ} \mathrm{F}$ temperature steps, the resulting errors in $U$ are about $10 \%$ and $6 \%$. Corresponding errors in diffusivity, when manual computation was used, are given in Table A-1.

\section{H. Errors Arising From Variation of Diffusivity with Temperafure}

In the manual calculations, it is assumed that the diffusivity is constant during a test. Results of several tests on a sample (Fig. 7-9) show, however, that the diffusivity varies perhaps $6 \%$ per $100^{\circ} \mathrm{F}$ in air and $10 \%$ in vacuum. The calculation gives some sort of average value for the temperature range of the test; this is estimated to differ 
from the diffusivity at the mean temperature by 10 to $25 \%$ of the above variation.

This error does not arise with machine computation, in which conductivity is considered to be a function of temperature.

\section{Errors Arising From Variation of Specific Heat with Temperature}

An average value of the specific heat over the test range was used in manual calculations of conductivity. Experimentally, the specific heat varied about $10 \%$ per $100^{\circ} \mathrm{F}$ (Fig. 5). The conductivity calculated may differ from that at the mean temperature by 10 to $25 \%$ of this variation. In machine calculations, the specific heat was taken as a function of temperature.

\section{J. Errors Arising From Uncertainties in Specific Heaf}

The experimental error in measuring specific heat, in the range 0 to $200^{\circ} \mathrm{F}$, is estimated at $5 \%$. For some of the conductivity determinations, specific heat down to $-100^{\circ} \mathrm{F}$ was needed. The extrapolation (Fig. 5) is estimated to be good to $10 \%$.

Resulting errors in calculated conductivity are equal to those in specific heat. No error in diffusivity is introduced, as specific heat values were not used in the diffusivity determination.

\section{REFERENCES}

I. Petit, E. and S. B. Nicholson, "Lunar Radiation and Temperatures," Astro-Physical Journal, Vol. 71, 1930.

2. Jaeger, J. C., "Sub-surface Temperatures on the Moon," Nature, p. 1316, May 9, 1959.

3. Shorthill, R. W., and J. M. Saari, "Lunar Infrared Temperature Measurements During September 4, 5, and 6, 1960," Boeing Airplane Company, Report D72550-1 (USAF Report BMD-TR-59-9), January 30, 1960.

4. Roddy, D. J., J. B. Rittenhouse, and R. F. Scott, “Dynamic Penetration Studies in Crushed Rock under Atmospheric and Vacuum Conditions," Technical Report No. 32-242, Jet Propulsion Laboratory, Pasadena, California.

5. Jakob, M., Heat Transfer, Vol. 1, J. Wiley and Sons, New York, 1955.

6. Russell, T. F., "Some Mathematical Considerations on the Heating and Cooling of Steels," pp. 149-187, First Report, Alloy Steels Research Committee. Iron and Steel Institute, London, 1936.

7. Goldsmith, A., T. E. Waterman, and H. J. Hirschhorn, Handbook of Thermophysical Properties of Solid Materials, Vol. II, MacMillan, New York, 1961.

8. Smithsonian Institute Physical Tables, Vol. 120, Ninth Edition, 1956.

9. Kersten, M. S., "Thermal Properties of Soils," Engineering Experiment Station Bulletin 28, University of Minnesota, 1949.

10. Chemical Engineers Handbook, McGraw Hill, New York, 1950.

11. Woodside, W., and J. H. Messmer, "Thermal Conductivity of Unconsolidated Sands," Journal of Applied Physics, Vol. 32, No. 9, September 1961. 